\title{
The Impact of Hyperoxia Treatment on Neurological Outcomes and Mortality in Moderate to Severe Traumatic Brain Injured patients
}

\author{
Raymond Khan*, Sarah Alromaih, Hind Alshabanat, Nosaiba Alshanqiti, Almaha \\ Aldhuwaihy, Sarah Abdullah Almohanna, Muna Alqasem, Hasan Al-Dorzi \\ King Saud bin Abdulaziz University for Health Sciences College of Medicine, Riyadh, Saudi Arabia
}

\begin{abstract}
Background: Traumatic brain injury is a leading cause of morbidity and mortality worldwide. The relationship between hyperoxia and outcomes in patients with TBI remains controversial. We assessed the effect of persistent hyperoxia on the neurological outcomes and survival of critically ill patients with moderate-severe TBI. Method: This was a retrospective cohort study of all adults with moderate-severe TBI admitted to the ICU between 1st January 2016 and 31st December 2019 and who required invasive mechanical ventilation. Arterial blood gas data was recorded within the first 3 hours of intubation and then after 6-12 hours and 24-48 hours. The patients were divided into two categories: Group I had a $\mathrm{PaO} 2<120 \mathrm{mmHg}$ on at least two ABGs undertaken in the first twelve hours post intubation and Group II had a PaO2 $\geq 120 \mathrm{mmHg}$ on at least two ABGs in the same period. Multivariable logistic regression was performed to assess predictors of hospital mortality and good neurologic outcome (Glasgow outcome score $\geq 4$ ). Results: The study included 309 patients: 54.7\% ( $n=169)$ in Group I and 45.3\% $(n=140)$ in Group II. Hyperoxia was not associated with increased mortality in the ICU $(20.1 \%$ vs. $17.9 \%, p=0.62)$ or hospital $(20.7 \%$ vs. $17.9 \%, p=0.53)$, moreover, the hospital discharge mean (SD) Glasgow Coma Scale (11.0(5.1) vs. 11.2(4.9), $p=0.70$ ) and mean (SD) Glasgow Outcome Score (3.1(1.3) vs. 3.1(1.2), $\mathrm{p}=0.47$ ) were similar. In multivariable logistic regression analysis, persistent hyperoxia was not associated with increased mortality (adjusted odds ratio [aOR] $0.71,95 \% \mathrm{Cl} 0.34-1.35, \mathrm{p}=0.29$ ). PaO2 within the first 3 hours was also not associated with mortality: $121-200 \mathrm{mmHg}$ : aOR 0.58, 95\% Cl 0.23-1.49, $\mathrm{p}=0.26$; 201300mmHg: aOR 0.66, 95\% Cl 0.27-1.59, $\mathrm{p}=0.35$; 301-400mm $\mathrm{mg}$ : aOR 0.85, 95\% Cl 0.31-2.35, $\mathrm{p}=0.75$ and $>400 \mathrm{mmHg}$ : aOR 0.51, 95\% Cl 0.18-1.44, p=0.20; reference: $\mathrm{PaO} 260-120 \mathrm{mmHg}$ within 3 hours. However, hyperoxia $>400 \mathrm{mmHg}$ was associated with being less likely to have good neurological $(G O S \geq 4$ ) outcome on hospital discharge (aOR 0.36 , $95 \% \mathrm{Cl}$ 0.13-0.98, p=0.046; reference: $\mathrm{PaO} 260-120 \mathrm{mmHg}$ within 3 hours. Conclusion: In intubated patients with moderate-severe $\mathrm{TBI}$, hyperoxia in the first 48 hours was not independently associated with hospital mortality. However, $\mathrm{PaO} 2>400 \mathrm{mmHg}$ may be associated with a worse neurological outcome on hospital discharge.
\end{abstract}

Keywords: traumatic brain injury, hyperoxia, mechanical ventilation, intensive care

Received: 3 January 2021 / Accepted: 3 May 2021

\section{INTRODUCTION}

Traumatic Brain Injury (TBI) is the leading cause of mortality and disability worldwide among the young population [1]. However, the true magnitude of this problem may be even greater than perceived, as a significant number of patients survive hospitalization but remain debilitated or ultimately succumb to complications from their injuries [2]. Severe TBI has a mortality rate of up to $30-40 \%$ and can cause significant physi- cal, psychosocial, and social deficits in up to $60 \%$ of patients [3]. Therefore, implementing interventions that improve outcomes are of paramount importance.

Currently, acute management of patients after TBI targets physiologic parameters to minimize secondary brain injury. This secondary injury is precipitated by ischemia resulting from decreased cerebral blood flow $(\mathrm{CBF})$ and is particularly likely to occur in the first twenty-four hours after injury [4]. Cerebral hypoxia $\left(\mathrm{PaO}_{2}<60 \mathrm{mmHg}\right)$ caused by cerebral hypoper- 
fusion, is associated with adverse outcomes in TBI [5]. In order to combat brain tissue hypoxia there has been a shift by some clinicians to use hyperoxia treatment $\left(\mathrm{PaO}_{2}>100 \mathrm{mmHg}\right.$ or $\left.13.3 \mathrm{kPa}\right)$ in order to improve oxygen delivery [6].

Since its discovery in 1770 , and later as treatment in the acute care setting in 1885, supplemental oxygen $\left(\mathrm{O}_{2}\right)$ has remained essential in the management of hypoxia [7].

As a consequence of ensuring optimal oxygen delivery in critically ill patients this "drug" has become a cornerstone of many resuscitation protocols and liberal use of supplemental oxygen is common [8].

Hence, many health care practitioners are more likely to accept supernormal arterial $\mathrm{O}_{2}$ levels, inattentive to any possible toxicity $[6,8]$.

Arterial hyperoxia has been shown to induce vasoconstriction and reduce cardiac output, which may impair blood flow to vital organs [9]. Also, exposure to high fractions of inspired oxygen following resuscitation amplifies the production of oxygen free radicals, resulting in neuronal injury via calcium influx causing excitotoxic damage or oxidative damage to the electron transport chain leading to decrease ATP production and subsequent activation of apoptotic pathways [8, $10,11]$.

Further, in one study even exposure to moderate hyperoxia $\left(\mathrm{FiO}_{2}=40 \%\right)$ was associated with inflammation, tissue necrosis and apoptosis in endothelial cells [12].

Hyperoxia $\left(\mathrm{PaO}_{2}>487 \mathrm{mmHg} / 64.9 \mathrm{kPa}\right)$ has been associated with higher mortality in a retrospective cohort study comprising 3,420 patients with severe TBI [13]. Similar findings were observed in a multicentre study among 1,212 mechanically ventilated patients suffering from TBI, where hyperoxia $\left(\mathrm{PaO}_{2}\right.$ $>300 \mathrm{mmHg} / 40.0 \mathrm{kPa}$ ) within 24 hours after admission to the ICU was independently associated with higher in-hospital mortality [14]. Brenner, et al. (2015) in their study of 1547 severe TBI patients, showed in a logistic regression model that mortality (OR 1.56, 95\% CI 1.18-2.07, p 0.002) and hospital length of stay (OR $0.74,95 \%$ CI $0.58-1.13$, p 0.01) were significantly worse for hyperoxic $\left(\mathrm{PaO}_{2}>200 \mathrm{mmHg} / 26.7 \mathrm{kPa}\right)$ patients [15]. In contrast, Raj et al. (2013) found in 1,116 patients with moderate-severe TBI that hyperoxia $\left(\mathrm{PaO}_{2}>100 \mathrm{mmHg} / 13.3 \mathrm{kPa}\right)$ was not predictive of 6-month mortality [1]. Russell et al. (2017) observed among their 471 patients with TBI that the maximum
$\mathrm{PaO}_{2}$ was $133 \mathrm{mmHg}$ among survivors and $152 \mathrm{mmHg}$ among non-survivors ( $\mathrm{p}$ 0.19). Further, analysis reveals that $\mathrm{PaO}_{2}$ was not related to increased mortality (OR 1.27, 95\% CI 0.72 - 2.25, p 0.85). [2] Likewise, Fujita et al. (2017) conducted a post-hoc analysis of 129 patients and found that $\mathrm{PaO}_{2}$ was significantly greater in patients with favourable neurological outcomes than in patients with unfavourable neurological outcomes $\left(\mathrm{PaO}_{2}: 252 \pm 122\right.$ vs. $\left.202 \pm 87 \mathrm{~mm} \mathrm{Hg}, p 0.008\right)$, and $\mathrm{PaO}_{2}$ was independently associated with survival following severe TBI [16]. Finally, Asher et al. (2013) noticed a $\mathrm{PaO}_{2}$ threshold between $250-486 \mathrm{mmHg}$ during the first 72 hours after injury was associated with improved all-cause survival in patients with severe TBI [17]. Additionally, in two recent meta-analyses the authors found that, ICU mortality, 6-month mortality, and failure to discharge home were not significantly associated with arterial hyperoxia $[9,18]$.

Substantial clinical uncertainty still persists in regard to the benefit or harm of hyperoxia in TBI patients. This uncertainty coupled with the immense burden of TBI in the Kingdom of Saudi Arabia has led us to perform a prospective cohort study to ascertain if persistent hyperoxia $\left(\mathrm{PaO}_{2}>120 \mathrm{mmHg}\right)$ in the first 24 hours of admission would affect the outcomes of moderate-severe TBI patients. We believe that this data may yield vital information needed to manage our patients and it may add some clarity to the fog surrounding hyperoxia that still exist today.

\section{Methods}

\section{Patients and Setting}

This was a retrospective cohort study of all consecutive patients with moderate-severe TBI that were admitted to the adult ICUs at King Abdulaziz Medical City, a 1000-bed tertiary care centre in Riyadh, Saudi Arabia. The units were covered by board-certified intensivists with onsite coverage 24 hours daily, and a nurse-topatient ratio of approximately 1:1. The hospital was accredited by the Joint Commission International and had active Trauma and Neurosurgical teams.

The study population included all adult patients, who were admitted to the ICU with moderate-to-severe TBI and required intubation from January 1st 2016 to December 31st, 2019. Patients who were admitted to the ICU for less than 72 hours, those labelled no code, comfort care, supportive care or brain dead, and those 
with incomplete medical records, were excluded from the study.

The Institutional Review Board and of the Ministry of National Guard Health Affairs, Riyadh, Saudi Arabia, approved this study and waived the requirement for informed consent.

\section{Data Collection}

A list was generated of all patients admitted to the ICU that fulfilled the inclusion and exclusion criteria.

Data was obtained from the computer chart for the analysis. These data include demographic characteristics, source of ICU admission, severity of illness on ICU admission assessed by Injury Severity score (ISS), Revised Trauma Score (RTS), Shock Index (SI) and The International Mission for Prognosis and Analysis of Clinical Trials (IMPACT) in TBI -core model (using age, motor function and pupil response), admission and discharge Glasgow coma score, laboratory parameters, arterial blood gas, computerized tomography (CT) findings, therapeutic intervention, ICU and hospital mortality, hospital length of stay and need for tracheostomy. Additionally, Glasgow Outcome Score (GOS) was calculated on the hospital discharge day. All arterial blood gas analysis measurements were obtained through arterio- puncture or arterial catheters for clinical purposes during the first $48 \mathrm{~h}$ of admission were recorded. The $\mathrm{PaO}_{2}$ on intubation and within 3-6, 1224 and 48 hours, the corresponding fraction of inspired oxygen $\left(\mathrm{FiO}_{2}\right)$, and Positive End Expiratory Pressures (PEEP) were documented. The study data were collected on a data collection sheet by the co-investigators, without any patient identifiers and were stored securely with the Principal Investigator.

Hyperoxia was defined as a $\mathrm{PaO}_{2}>120 \mathrm{mmHg}[19$, 20]. Patients were categorized into two groups depending on the $\mathrm{PaO}_{2}$ on $\mathrm{ABG}$ done in the first 48-hours of intubation.

Group 1 were defined as having non-persistent hyperoxia: patients that may have had a $\mathrm{PaO}_{2}$ greater than $120 \mathrm{mmHg}$ on initial ABG undertalekn within $20 \mathrm{~min}$ utes of intubation, but on repeat ABGs within 3 hours of intubation the $\mathrm{PaO}_{2}$ was less than $120 \mathrm{mmHg}$.

Group11 were defined as having persistent hyperoxia: patients that had an initial $\mathrm{PaO}_{2}$ greater that $120 \mathrm{mmHg}$ and two or more consecutive ABGs with $\mathrm{PaO}_{2}$ greater than $120 \mathrm{mmHg}$ within 24-hours of intubation. These patients were followed and their outcomes were then recorded.

\section{Statistical Analysis}

Data were analysed using SPSS version 15.0 (SPSS Inc, Chicago, Illinois). Continuous variables were presented as means (SD) and categorical variables as frequencies and percentages. The Chi-squared or Fisher's exact test was used to compare qualitative variables and the Student $t$-test or ANOVA to compare quantitative variables. The significance level was set at $\alpha=0.05$.

In the multivariable logistic regression analysis for the predictors of hospital mortality and neurologic outcome the following variables were entered in the model: age, Injury Severity Score, arrival Glasgow Coma Scale, systolic blood pressure $>90 \mathrm{mmHg}$ presence of midline shift $>5 \mathrm{~mm}$ on brain CT.

In the multivariable logistic regression analysis for the predictors of hospital mortality and neurologic outcome, the following variables were entered in the model: age, Injury Severity Score, arrival Glasgow Coma Scale, systolic blood pressure $>90 \mathrm{mmHg}$ presence of midline shift $>5 \mathrm{~mm}$ on brain CT.

Multivariable logistic regression analysis was performed using two models. In the first model, we analysed if persistent hyperoxia would affect hospital mortality or neurological outcome. While, in the second model we tested if specific range of $\mathrm{PaO}_{2}$ would alter patients' outcome.

The hospital mortality rates were compared in certain subgroups, which were selected based on clinical relevance. The results were presented as odds ratio (OR) with 95\% confidence interval (CI).

\section{RESULTS}

Baseline characteristics of the cohort are presented in Table 1. The patients were mostly young men. There were no significant differences between Group I and II in Injury Severity Score [29.9(6.8) vs. 30.2(8.2), 0.74], Revised Trauma Score [5.3(1.2) vs. 5.4(1.1), 0.63] and IMPACT mortality [29.2(18.7) vs. 26.5(16.8), $\mathrm{p}=0.19$ ].

Isolated head injury $(29.0 \%$ vs. $33.4 \%, 0.39)$ and midline shift $\geq 5 \mathrm{~mm}$ ( $11.2 \%$ vs. $16.4 \%, \mathrm{p}=0.19)$ were comparable between the groups.

The management strategies, such as intravenous tranexamic acid (29.8\% vs. $32.4 \%, 0.62)$, ICP insertion $(14.1$ vs. $19.2,0.24)$ and initiation of head-injury protocol $(86.5 \%$ vs $70.4 \%, 0.74)$ were nosignificantly different between the two groups. 
Table 1. Baseline Characteristics

\begin{tabular}{|c|c|c|c|c|}
\hline Variables & $\begin{array}{c}\text { All } \\
N=309\end{array}$ & $\begin{array}{l}\text { Group I } \\
N=169\end{array}$ & $\begin{array}{c}\text { Group II } \\
N=140\end{array}$ & p-value \\
\hline Age (years), mean(SD) & $31.4(12.4)$ & $32.2(13.0)$ & $30.6(11.6)$ & 0.28 \\
\hline Male gender, N (\%) & $293(94.8)$ & $164(97.0)$ & $129(92.1)$ & 0.53 \\
\hline Body Mass Index $\left.9 \mathrm{~kg} / \mathrm{m}^{2}\right)$, mean(SD) & $23.7(5.3)$ & $24.5(5.60$ & $22.8(4.7)$ & 0.07 \\
\hline Ideal Body Weight (kg), mean(SD) & $65.0(6.5)$ & $65.4(6.7)$ & $64.6(6.4)$ & .028 \\
\hline \multicolumn{5}{|l|}{ Source of admission, N (\%) } \\
\hline Emergency Department & $260(84.1)$ & $147(87.0)$ & $113(80.7)$ & 0.13 \\
\hline Operating Room & 49 (15.9) & $22(13.0)$ & $27(19.3)$ & \\
\hline \multicolumn{5}{|l|}{ Markers of Injury Severity, mean(SD) } \\
\hline Injury Severity Score, points & $30.0(7.5)$ & 29.996.8) & $30.2(8.2)$ & 0.74 \\
\hline Revised Trauma Score, points & $5.3(1.1)$ & $5.3(1.2)$ & $5.4(1.1)$ & 0.63 \\
\hline Shock Index & $0.86(0.3)$ & $0.9(0.4)$ & $0.8(0.3)$ & 0.19 \\
\hline IMPACT mortality, \% & 27.9(17.9) & 29.2(18.7) & 26.5(16.8) & 0.19 \\
\hline IMPACT outcome, \% & $41.7(20.5)$ & $43.1(20.9)$ & $40.1(19.9)$ & 0.20 \\
\hline \multicolumn{5}{|l|}{ Physiological Parameters, mean(SD) } \\
\hline Systolic blood pressure, $\mathrm{mmHg}$ & $128.3(26.5)$ & $128.4(27.4)$ & $128.1(25.6)$ & 0.91 \\
\hline MAP, mmHg & $94.4(22.6)$ & 93.8(23.9) & $95.1(21.1)$ & 0.60 \\
\hline Heart rate, beats/min & $104.7(28.2)$ & $106.8(28.7)$ & $102.2(27.5)$ & 0.15 \\
\hline Respiratory rate, breaths/min & $24.3(7.0)$ & $24.7(7.2)$ & $23.8(6.7)$ & 0.31 \\
\hline Oxygen saturation, \% & $95.7(8.7)$ & $95.0(10.3)$ & $96.5(6.3)$ & 0.12 \\
\hline Temperature, ${ }^{\circ} \mathrm{C}$ & $36.7(0.7)$ & $36.7(0.7)$ & $36.7(0.7)$ & 0.67 \\
\hline CVP, mmHg & $10.7(4.6)$ & $11.6(5.0)$ & $9.6(3.8)$ & 0.01 \\
\hline Arrival GCS & $5.9(2.8)$ & $5.9(2.9)$ & $5.9(2.7)$ & 0.88 \\
\hline GCS 9-12, N(\%) & $55(17.8)$ & $31(18.3)$ & 25 17.9) & 0.53 \\
\hline $\mathrm{GCS} \leq 8, \mathrm{~N}(\%)$ & 253(81.9) & 138(81.7) & 115(82.1) & \\
\hline \multicolumn{5}{|l|}{ Laboratory Parameters, mean(SD) } \\
\hline White blood cell count, 109/L & $17.3(6.8)$ & $17.5(7.3)$ & $17.1(6.2)$ & 0.68 \\
\hline Hemoglobin, gm/L & $139.3(25.0)$ & $0.44(0.07)$ & $0.41(0.1)$ & 0.04 \\
\hline Platelets, $10^{9} / \mathrm{L}$ & $271.9(90.7)$ & $274(90.5)$ & 270(91.3) & 0.70 \\
\hline Sodium, mmol/L & 139.6(4.1) & 139.6(4.2) & $139.7(4.0)$ & 0.81 \\
\hline Chloride, mmol/L & $108.2(8.6)$ & $108.5(6.2)$ & $107.8(10.8)$ & 0.49 \\
\hline Creatinine, umol/L & $90.1(61.2)$ & $94.3(78.7)$ & $85.0(27.9)$ & 0.18 \\
\hline Lactic Acid, mmol/L & $3.2(2.9)$ & $3.4(3.0)$ & $3.0(2.9)$ & 0.34 \\
\hline AST, U/L & $111.8(163.8)$ & $135.3(207.0)$ & $83.9(80.6)$ & 0.06 \\
\hline $\mathrm{ALT}, \mathrm{U} / \mathrm{L}$ & $81.6(134.1)$ & 100.4(169.6) & $59.3(66.0)$ & 0.07 \\
\hline \multicolumn{5}{|c|}{ Respiratory and Ventilator Parameters, mean(SD) } \\
\hline Tidal volume, $\mathrm{mL}$ & $425(37.9)$ & $427(42.7)$ & $422(30.8)$ & 0.24 \\
\hline Tidal volume per IDBW, mL/kg & $6.6(0.8)$ & $6.6(0.8)$ & $6.6(0.8)$ & 0.90 \\
\hline $\mathrm{FiO}_{2}, \%$ & $0.8(0.3)$ & $0.8(0.3)$ & $0.8(0.3)$ & 0.93 \\
\hline PEEP, $\mathrm{mmHg}$ & $5.9(3.2)$ & $6.1(3.8)$ & $5.7(2.1)$ & 0.31 \\
\hline $\mathrm{pH}$ & $7.29(0.9)$ & $7.29(0.1)$ & $7.29(0.1)$ & 0.44 \\
\hline $\mathrm{PaCO}_{2}, \mathrm{mmHg}$ & $4 . .2(9.3)$ & $43.8(9.9)$ & $42.5(8.5)$ & 0.23 \\
\hline $\mathrm{PaO}_{2}, \mathrm{mmHg}$ & $228.4(143.4)$ & $175.8(117.8)$ & $291.9(146.2)$ & $<0.001$ \\
\hline $\mathrm{PaO}_{2} / \mathrm{FiO}_{2}$ ratio, & $316(237)$ & $240(171)$ & $407.5(272.5)$ & $<0.001$ \\
\hline
\end{tabular}


Table 1 (Cont.)

\begin{tabular}{|c|c|c|c|c|}
\hline Variables & $\begin{array}{c}\text { All } \\
N=309\end{array}$ & $\begin{array}{l}\text { Group I } \\
N=169\end{array}$ & $\begin{array}{c}\text { Group II } \\
N=140\end{array}$ & p-value \\
\hline \multicolumn{5}{|l|}{ CT Head Findings, N(\%) } \\
\hline Epidural Hematoma & $26(8.4)$ & $16(9.5)$ & $10(7.1)$ & 0.50 \\
\hline Subdural Hematoma & 125(40.5) & $69(40.8)$ & $56(40.0)$ & 0.88 \\
\hline Subarachnoid hemorrhage & 115(37.2) & $67(39.6)$ & $48(34.3)$ & 0.33 \\
\hline Intraparenchymal Hemorrhage/Contusion & $151(48.9)$ & $81(47.9)$ & $70(50.0)$ & 0.72 \\
\hline Intraventricular Hemorrhage & 46(14.9) & 26(15.4) & $20(14.3)$ & 0.79 \\
\hline Cerebral Edema & 107(34.6) & $54(32.0)$ & $53(37.9)$ & 0.28 \\
\hline Midline Shift $\geq 5 \mathrm{~mm}$ & $42(13.6)$ & 19(11.2) & $23(16.4)$ & 0.19 \\
\hline Axonal Injury & $20(6.5)$ & $11(6.5)$ & $9(6.4)$ & 0.98 \\
\hline Herniation & $30(9.7)$ & $15(8.9)$ & $15(10.7)$ & 0.59 \\
\hline Normal findings & $50(16.2)$ & $25(14.8)$ & 25(17.9) & 0.47 \\
\hline Isolated Head Injury, N (\%) & $96(30.1)$ & 49(29.0) & $47(33.6)$ & 0.39 \\
\hline \multicolumn{5}{|l|}{ Management } \\
\hline Fluid balance at 24 hours $(\mathrm{mL})$, mean \pm SD & $3372(2528)$ & $3435(2678)$ & $3298(2343)$ & 0.64 \\
\hline \multicolumn{5}{|l|}{ Blood products (Units), mean(SD) } \\
\hline Red blood cells & $2.1(3.9)$ & $1.8(3.8)$ & $2.3(3.9)$ & 0.26 \\
\hline Platelets & $6.2(4.9)$ & $7.5(5.8)$ & $5.1(3.6)$ & 0.05 \\
\hline Fresh frozen plasma & $5.8(4.6)$ & $6.4(5.1)$ & $5.3(3.6)$ & 0.27 \\
\hline Tranexamic acid, N(\%) & & $50(29.8)$ & $45(32.4)$ & 0.62 \\
\hline Vasopressor index, mean(SD) & $3.5(0.7)$ & $3.5(0.7)$ & $3.5(0.6)$ & 0.46 \\
\hline ICP Monitoring, N(\%) & $47(15.2)$ & $22(14.1)$ & $25(19.2)$ & 0.24 \\
\hline Hypertonic saline, N(\%) & $155(50.2)$ & $87(59.6)$ & $68(57.1)$ & 0.69 \\
\hline Head injury protocol, N(\%) & $165(53.4)$ & $89(86.5)$ & $76(70.4)$ & 0.75 \\
\hline
\end{tabular}

Table 2 describes the various outcomes measures.

Persistent hyperoxia was not associated with a prolonged ICU or hospital length of stay or duration of mechanical ventilator. Additionally, hyperoxia was not associated with increased ICU stay $(20.1 \%$ vs. $17.9 \%$, p 0.62 ) or hospital mortality (20.7\% vs. $17.9 \%$, p 0.53 ).

Further, the mean (SD) Glasgow Coma Scale on hospital discharge [11.0(5.1) vs. 11.2(4.9), p 0.70] and

Table 2. Hospital outcomes for cohort.

\begin{tabular}{lcccc} 
Variables & $\begin{array}{c}\text { All } \\
\mathbf{N}=\mathbf{3 0 9}\end{array}$ & $\begin{array}{c}\text { Group I } \\
\mathbf{N = 1 6 9}\end{array}$ & $\begin{array}{c}\text { Group II } \\
\mathbf{N = 1 4 0}\end{array}$ & p-value \\
\hline ICU Length of stay (days), mean(SD) & $15.9(18.7)$ & $17.1923 .2)$ & $14.5(11.2)$ & 0.23 \\
Hospital length of stay (days), mean(SD) & $54.3(76.2)$ & $60.2(86.5)$ & $47.2(61.3)$ & 0.13 \\
Duration on MV (days), mean(SD) & $10.1(8.4)$ & $10.6(6.3)$ & $9.5(10.3)$ & 0.25 \\
Tracheostomy, N (\%) & $80(25.9)$ & $51(34.2)$ & $29(23.8)$ & 0.06 \\
ICU mortality, N (\%) & $59(19.1)$ & $34(20.1)$ & $25(17.9)$ & 0.62 \\
Hospital mortality, N (\%) & $60(19.4)$ & $35(20.7)$ & $25(17.9)$ & 0.53 \\
ICU discharge GCS, mean(SD) & $9.2(4.7)$ & $8.9(4.8)$ & $9.5(4.7)$ & 0.33 \\
Hospital discharge GCS, mean(SD) & $11.1(5.0)$ & $11.0(5.1)$ & $11.2(4.9)$ & 0.70 \\
Hospital discharge GOS, mean(SD) & $3.1(1.2)$ & $3.1(1.3)$ & $3.1(1.2)$ & 0.47 \\
Hospital discharge GOS <4 & $206(66.7)$ & $113(66.9)$ & $93(66.4)$ & 0.92 \\
Hospital discharge GOS $\geq 4$ & $103(33.3)$ & $56(33.1)$ & $47(33.6)$ & 0.94 \\
\hline
\end{tabular}


the mean (SD) Glasgow Outcome Scores [3.1(1.3) vs. $3.1(1.2)$, p 0.47] were not statistically significant between the groups.

The unadjusted outcomes for different $\mathrm{PaO}_{2}$ ranges in the first three hours of intubation are presented in Figure 1.

Compared to those with $\mathrm{PaO}_{2}$ of $60-120 \mathrm{mmHg}$, patients with $\mathrm{PaO}_{2}>400 \mathrm{mmHg}$ had a significantly shorter ICU length of stay [65.1(93.4) vs. 33.8(36.2), p 0.025], better ICU discharge Glasgow Coma Scale [8.6(4.7) vs. 10.7(4.7), p 0.01], and hospital discharge Glasgow Coma Scale [10.6(5.2) vs. 12.5(4.4), p 0.03].

The ICU mortality for those patients with a $\mathrm{PaO}_{2}$ of $60-120 \mathrm{mmHg}$ in the first 3 hours of intubation was not significantly different compared to those with $\mathrm{PaO}_{2}$ $>120 \mathrm{mmHg}$ at $0-3$ hours $(18.7 \%$ vs. $18.2 \%, \mathrm{p} 0.92)$ and those that remained with $\mathrm{PaO}_{2}>120 \mathrm{mmHg}$ at 3-12 hours ( $18.7 \%$ vs. $15.6 \%$ p 0.56 ).

We also investigated if using the threshold of $\mathrm{a} \mathrm{Pa}_{2}$ $>100 \mathrm{mmHg}$ to define hyperoxia would yield a difference in ICU mortality. However, no difference was detected in ICU mortality between those with a $\mathrm{PaO}_{2} 60$ $100 \mathrm{mmHg}$ compared to those with a $\mathrm{PaO}_{2}>100 \mathrm{mmHg}$ ( $22.1 \%$ vs. $17.1 \%$, p 0.42$)$.

Table 3. Hospital outcomes in subgroup analysis.
In the multivariable logistic regression analysis, a midline shift $\geq 5 \mathrm{~mm}$ was an independent predictor of mortality (OR: 5.25; 95\% CI: 2.47-11.18, p <0.001), while persistent hyperoxia was not associated with increased mortality (OR 0.71, 95\% CI 0.34-1.35, p 0.29).

In the second model different ranges of $\mathrm{PaO}_{2}$ were evaluated to identify if they contributed to mortality. Again, hyperoxia in any category $\left(\mathrm{PaO}_{2} 60-120 \mathrm{mmHg}\right.$ : baseline, 121-200mmHg: OR 0.58, 95\% CI 0.23-1.49, p 0.26; 201-300mmHg: OR 0.66, 95\% CI, 0.27-1.59, p 0.35; 301-400mmHg: OR 0.85, 95\% CI 0.31-2.35, p 0.75 and $>400 \mathrm{mmHg}$ : OR $0.51,95 \%$ CI $0.18-1.44, \mathrm{p} 0.20$ ) were not independent predictors of mortality.

However, hyperoxia $>400 \mathrm{mmHg}$ was associated with being less likely to have good neurological, Glasgow Outcome Scores $\geq 4$ outcome on hospital discharge (OR 0.36, 95\% CI 0.13-0.98, p 0.46), determined by Glasgow Outcome Scores.

In subgroups analysis for hospital admission Glasgow Coma Scale $<9$, isolated TBI, initiation of head injury protocol and ratio of arterial oxygen partial pressure to fractional inspired oxygen within first 3 hours $>300$, there were no significant differences in both mortality and neurological outcomes (Table 3 ) between the groups.

\begin{tabular}{|c|c|c|c|c|c|c|}
\hline \multirow{2}{*}{ Variables } & \multicolumn{3}{|c|}{ Hospital Mortality N (\%) } & \multicolumn{3}{|c|}{ Hospital discharge GOS, mean(SD) } \\
\hline & Group I & Group II & P value & Group I & Group II & P value \\
\hline GCS $<9$ & $33(23.9)$ & $24(20.9)$ & 0.56 & $3.0(1.3)$ & $3.0(1.2)$ & 0.92 \\
\hline Isolated TBI & $11(22.4)$ & $9(19.1)$ & 0.69 & $2.8(1.2)$ & $3.2(1.3)$ & 0.94 \\
\hline HIP & $22(24.7)$ & $16(21.1)$ & 0.58 & $3.0(1.3)$ & $3.1(1.2)$ & 0.61 \\
\hline PF ratio $<300$ & 27 923.1) & $15(29.4)$ & 0.38 & $3.0(1.3)$ & $2.8(1.3)$ & 0.31 \\
\hline PF ratio >300 & $8(15.4)$ & $10(11.2)$ & 0.48 & $3.3(1.1)$ & $3.4(1.0)$ & 0.58 \\
\hline $\mathrm{SAH}$ & 20 (29.9) & $14(29.2)$ & 0.94 & $2.7(1.3)$ & $2.8(1.1)$ & 0.87 \\
\hline $\mathrm{SDH}$ & $21(30.4)$ & $15(26.8)$ & 0.65 & $2.7(1.3)$ & $2.9(1.3)$ & 0.42 \\
\hline
\end{tabular}

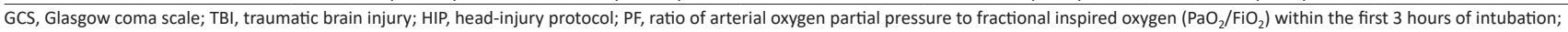
SAH, subarachnoid hemorrhage; SD, standard deviation; SDH, subdural hemorrhage.
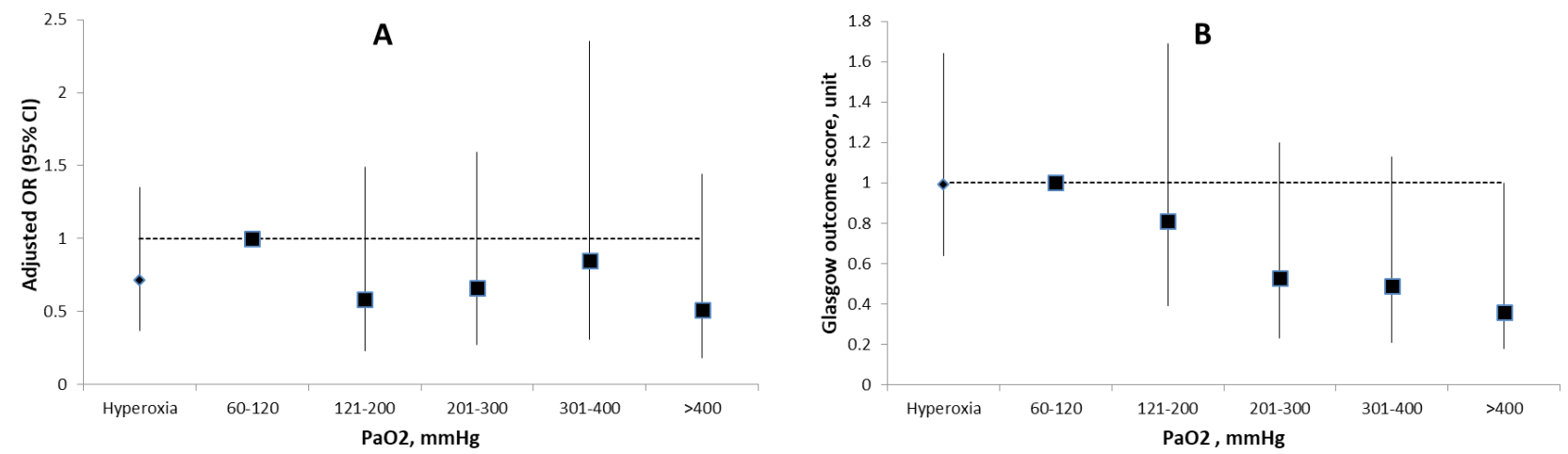

Fig. 1. Adjusted odd ratio for hospital mortality (A) and Glasgow outcome score $\geq 4$ (B) for persistent hyperoxia and different $\mathrm{PaO}_{2}$ ranges. 


\section{DISCUSSION}

We conducted a retrospective observational study, investigating the relationship between hyperoxia in the first 24 hours of intubation on mortality and functional outcomes in patient with moderate-severe TBI. Our data suggest that persistent hyperoxia $\left(\mathrm{PaO}_{2}>120 \mathrm{mmHg}\right)$ was not an independent predictor of hospital mortality or unfavourable neurological outcomes. Additionally, we did not detect an association in subgroups of patients with isolated TBI, GCS $<9$ or those on "head injury protocol". Finally, in analysing different ranges of $\mathrm{PaO}_{2}$ (60-120mmHg, 121-200mmHg, 201-300mmHg, $301-400 \mathrm{mmHg}$ and $>400 \mathrm{mmHg}$ ), none of the categories contribute to increased mortality, but patients with $\mathrm{PaO}_{2}>400 \mathrm{mmHg}$ within 3 hours of intubation were less likely to have good neurological outcomes, Glasgow Outcome Scores $\geq 4$ on hospital discharge compared with patients with $\mathrm{PaO} 260-120 \mathrm{~mm} \mathrm{Hg}$.

Substantial evidence suggests that hyperoxia can have harmful biological and physiological effects on humans. Elevated $\mathrm{PaO}_{2}$ may increase the formation of reactive oxygen species in the neuronal tissue via mitochondrial oxidoreductive process, xanthine/urate oxidase or phagocytes, which may attenuate oxidative and nitrosative stress, thereby favouring the induction of apoptotic neuronal death and necrosis, potentially contributing to poor neurological outcomes [2]. Further, supra-physiological levels of oxygen can cause cerebral vasoconstriction resulting in decreased cerebral blood flow (CBF), paradoxically lowering delivery of oxygen and other important substrates to the cerebral tissue [22].

Immediately following TBI, the metabolic demand of the brain increases, but oxygen delivery may decrease due to a reduction of CBF, increased ICP, and decreased oxygen diffusion caused by capillary endothelium oedema, secondary to the neuroinflammatory response [23]. This oxygen deficiency forces conversion to anaerobic metabolism, leading to depletion of cellular ATP. This crisis result in inadequate ATP needed for normal $\mathrm{Na}+/ \mathrm{K}+$ ATPase pump function, leading to calcium influx, release of excitatory neurotransmitters and mediators of programmed cell death [4]. Hyperoxia has been associated with improvements in intracranial pressure, brain tissue oxygenation, lactate concentration and lactate pyruvate ratio (creating a more aerobic metabolic profile) in TBI [24]. In fact, Ghosh et al. (2017) showed that hyperoxia in acute brain injury resulted in increased brain tissue $\mathrm{PaO}_{2}$, reduced lactate pyruvate ratio, increased cytochrome c oxidase and cerebral metabolic rates [25]. Furthermore, the combination of hyperbaric and normobaric hyperoxia in the treatment of severe TBI has been associated with improved markers of oxidative stress, and significant reduction in mortality and poor neurological outcomes [26]. This implies that hyperoxia may increase oxygen delivery to brain tissue and protect against secondary ischemic damage [4].

Our results are consistent with other studies, suggesting no association of hyperoxia and mortality in TBI patients $[1,2,16]$. Raj et al. (2013) using the Finnish Intensive Care Consortium database of mechanically ventilated patients with moderate-to-severe TBI, found no independent relationship between hyperoxia, define as $\mathrm{PaO}_{2}>100 \mathrm{mmHg}$ and 6-month mortality (OR $0.88,95 \%$ CI $0.63-1.22$, p 0.43) after adjusting for markers of illness severity [1]. In ventilated patients with severe TBI, Russell et al. (2017) detected no significant difference in the maximum $\mathrm{PaO}_{2}$ between survivors and non-survivors (141 vs. $148 \mathrm{mmHg}, \mathrm{p} 0.82$ ). Further, hyperoxia in the first 24 hours of intubation was not associated with increased mortality (OR 1.27 95\%CI 0.72-2.25, p 0.41) [2]. Post-hoc analyses of data from the Brain Hypothermia study revealed that $\mathrm{PaO}_{2}$ was higher in survivors and those with favourable neurological outcomes as measured by GOS than in non-survivors and those with unfavourable outcomes $\left(\mathrm{PaO}_{2}: 242\right.$ vs. $193 \mathrm{mmHg}, \mathrm{p} 0.022$ and $\mathrm{PaO}_{2}$ : 252 vs. $202 \mathrm{mmHg}$, p 0.008 - respectively) [16]. Asher et al. (2013) observed that in $\mathrm{PaO}_{2}$ range from 250$486 \mathrm{mmHg}$ in the first 72 hours post severe TBI was associated with a survival benefit (OR $0.46,95 \%$ CI 0.22 0.95).[17] Recently, O'Brian et al. (2018) extracted data from the Australian and New Zealand Intensive Care Society Centre for Outcome and Resource Evaluation Adult Patient Database for 24,148 TBI patients found that hyperoxia was not independently associated with greater in-hospital mortality [27].

Conversely, Davis et al. (2009) found in patients with severe TBI that extreme hyperoxia $\left(\mathrm{PaO}_{2} \geq 487 \mathrm{mmHg}\right)$ was associated with an increased mortality [13]. However, this study used an extremely high $\mathrm{PaO}_{2}$ as an arbitrary threshold and only included the first $\mathrm{PaO}_{2}$ measurement in their regression analysis models. In a single centre retrospective study Brenner et al. (2012) showed that hyperoxia $\left(\mathrm{PaO}_{2}>200 \mathrm{mmHg}\right)$ was associated with increased mortality, hospital length of stay, and decreased GCS [15]. Although this study used the mean 
$\mathrm{PaO}_{2}$ from $\mathrm{ABG}$ in the first 24 hours, it was not restricted to only mechanically ventilated patients, which may introduce bias, as it is possible that patients not on mechanical ventilation are likely to have less sever TBI and thus less likely to be hyperoxic. Rincon et al. (2014) in a multicentre cohort study of ventilated TBI patients found in multivariate analysis that hyperoxia $\left(\mathrm{PaO}_{2} \geq 300 \mathrm{mmHg}\right)$ was independently associated with higher in-hospital mortality [14]. This study used only the "worst" $\mathrm{PaO}_{2}$ which may be misleading as we found in our study that many patients may have an elevated $\mathrm{PaO}_{2}$ immediately post intubation, but this did not persist in subsequent ABGs repeated 1-3 hours later.

Clinical studies have yield conflicting data on the effect of hyperoxia on TBI patients. A meta-analysis in 2014 concluded that hyperoxia in TBI was associated with increased mortality [28].

However, a subsequent meta-analysis and meta regression of the same studies revealed in a that hyperoxia was not an independent predictor of mortality (OR $1.26,95 \%$ CI 0.85-1.88, 0.25) [9].

Moreover, a recent meta-analysis by $\mathrm{Ni}$ et al. (2019) found that hyperoxia did not contribute to higher mortality in patients with TBI, stroke, post cardiac surgery and mechanical ventilation, but the authors caution about the generalizability of the results due to the high heterogeneity of the studies available [18].

Our subgroup analysis for patients with arrival GCS $\leq 8$ and isolated TBI revealed that hyperoxia was not associated with increased ICU or hospital mortality. Analogous findings were reported by O'Brian et al. (2018) that in multivariable analysis, hyperoxia was not identified as an independent risk factor for mortality in isolated TBI [27].

The application of hyperoxia after TBI was demonstrated to improve brain tissue oxygenation by cerebral microdialysis, brain tissue oximetry, and oxygen-15 positron emission tomography. [29] As well, a randomized control trial exposing TBI patients to normobaric hyperoxia ( $\mathrm{FiO} 2 \mathrm{80} \%$ ), found that hyperoxia was associated with better 6 months neurological outcomes assessed by Glasgow Outcome Scores [30]. However, our data was more consistent with the findings of Davis et al. (2009) and Brenner et al. (2012) who also reported that hyperoxia was associated with worse functional outcomes $[13,15]$.

This study has several strengths. It used a relatively large database to extract patients with moderate-sever
TBI. We included only patients receiving mechanical ventilation, with multiple ABGs with the first 48 hours of intubation, ensuring that the cohort had significant injury and remained persistently hyperoxic for several hours. This was the first study of its kind in this patient population (Saudi Arabia). The data were collected by trained collectors and are unlikely to be subject to bias. We used validated markers for severity of illness, which allowed us to calculate adjusted mortality risk with varying $\mathrm{PaO} 2$ categories. We also performed sensitivity analysis in multiple subgroups to further substantiate our findings. Finally, we used Glasgow outcome scores to evaluate neurological outcomes. Despite this we acknowledge several limitations to this study. Firstly, this was a single centred study of mostly male patients, thus generalization of our findings should be cautious. Secondly, the study was observational, which limits any robust assessment of causation. Thirdly, our cohort consisted of some patients with multiple traumatic injuries, which may have tinted any analysis, however in those cases recorded as having isolated TBI, no significant association was noted between hyperoxia and mortality. Fourth, due to the retrospective nature of the study we were unable to assess long-term neurological outcome and our GOS was done at hospital discharge. Lastly, TBI encompasses a number of unique pathologies (e.g., SDH, SAH, diffuse axonal injury) and that although no differences were evident in isolated TBI and GCS $\leq 8$, it is highly conceivable that hyperoxia may impact each injury sub-type differently.

\section{CONCLUSION}

Our data revealed that persistent hyperoxia $\left(\mathrm{PaO}_{2}\right.$ $>120 \mathrm{mmHg}$ ) is not an independent predictor of mortality, but supraphysiological levels $\left(\mathrm{PaO}_{2}>400 \mathrm{mmHg}\right)$ may result in poor neurological outcomes. The current data about hyperoxia in TBI patients is tainted with multiple heterogeneous studies in which the threshold used to define hyperoxia ranges from $85-487 \mathrm{mmHg}$. Thus, currently the exact target for $\mathrm{PaO}_{2}$ in TBI remains unclear, until concert evidence emerges from well-designed randomized control studies.

\section{口AUTHOR'S CONTRIBUTION}

RK: Head of the project, acquisition of data, analytical plan, drafting of the manuscript and critical revision of the manuscript for important intellectual content, approval of the final version to be published. 
SAR: Data collection and entry, drafting of the manuscript and critical revision of the manuscript for important intellectual content, approval of the final version to be published.

HAS: Data collection and entry, drafting of the manuscript and critical revision of the manuscript for important intellectual content, approval of the final version to be published.

NAS: Data collection and entry, drafting of the manuscript and critical revision of the manuscript for important intellectual content, approval of the final version to be published.

AAD: Data collection and entry, drafting of the manuscript and critical revision of the manuscript for important intellectual content, approval of the final version to be published.

SAA: Data collection and entry, drafting of the manuscript and critical revision of the manuscript for important intellectual content, approval of the final version to be published.

MAQ: Data collection and entry, drafting of the manuscript and critical revision of the manuscript for important intellectual content, approval of the final version to be published.

HAD: Data Analysis, statistical modelling and calculations, drafting of the manuscript, critical revision of the manuscript for important intellectual content, approval of the final version to be published.

All authors agree to be accountable for all aspects of the work in ensuring that questions related to the accuracy or integrity of any part of the article are appropriately investigated and resolved

\section{- CONFLICT OF INTEREST}

None of the authors has any potential competing interests.

\section{ETHICS APPROVAL}

The Institutional Review Board and of the Ministry of National Guard Health Affairs, Riyadh, Saudi Arabia, approved this study and waived the requirement for informed consent.

\section{- REFERENCES}

1. Raj R, Bendel S, Reinikainen M, Kivisaari R, Siironen J, Lang $M$, Skrifvars $M$ : Hyperoxemia and long-term outcome after traumatic brain injury. Crit Care 2013;17(4):R177.

2. Russell DW, Janz DR, Emerson WL, et al: Early exposure to hyperoxia and mortality in critically ill patients with severe traumatic injuries. BMC Pulm Med 2017;17(1):29.

3. Khellaf A, Khan DZ, Helmy A: Recent advances in traumatic brain injury. J Neurol 2019;266(11):2878-2889.

4. Daly S, Thorpe M, Rockswold S, et al: Hyperbaric Oxygen Therapy in the Treatment of Acute Severe Traumatic Brain Injury: A Systematic Review. J Neurotrauma 2018, 35(4):623629.

5. Brain Trauma F, American Association of Neurological S, Congress of Neurological S: Guidelines for the management of severe traumatic brain injury. J Neurotrauma 2007;24 Suppl 1:S1-106.

6. Page D, Ablordeppey E, Wessman BT, et al: Emergency department hyperoxia is associated with increased mortality in mechanically ventilated patients: a cohort study. Crit Care 2018;22(1):9.

7. Vincent JL, Taccone FS, He X: Harmful Effects of Hyperoxia in Postcardiac Arrest, Sepsis, Traumatic Brain Injury, or Stroke: The Importance of Individualized Oxygen Therapy in Critically III Patients. Can Respir J 2017;2017:2834956.

8. Stolmeijer R, Bouma HR, Zijlstra JG, Drost-de Klerck AM, Ter Maaten JC, Ligtenberg JJM: A Systematic Review of the Effects of Hyperoxia in Acutely III Patients: Should We Aim for Less? Biomed Res Int 2018;2018:7841295.

9. Helmerhorst HJ, Roos-Blom MJ, van Westerloo DJ, de Jonge E: Association Between Arterial Hyperoxia and Outcome in Subsets of Critical Illness: A Systematic Review, Meta-Analysis, and Meta-Regression of Cohort Studies. Crit Care Med 2015;43(7):1508-1519.

10. Roberts BW, Kilgannon JH, Hunter BR, et al: Association Between Early Hyperoxia Exposure After Resuscitation From Cardiac Arrest and Neurological Disability: Prospective Multicenter Protocol-Directed Cohort Study. Circulation 2018;137(20):2114-2124.

11. Quintard H, Patet C, Suys T, Marques-Vidal P, Oddo M: Normobaric hyperoxia is associated with increased cerebral excitotoxicity after severe traumatic brain injury. Neurocrit Care 2015;22(2):243-250.

12. Hafner C, Wu J, Soto-Gonzalez L, et al: Moderate hyperoxia induces inflammation, apoptosis and necrosis in human umbilical vein endothelial cells: An in-vitro study. Eur J Anaesthesiol 2017;34(3):141-149.

13. Davis DP, Meade W, Sise MJ, Kennedy F, Simon F, Tominaga G, Steele J, Coimbra R: Both hypoxemia and extreme hyperoxemia may be detrimental in patients with severe traumatic brain injury. J Neurotrauma 2009;26(12):2217-2223.

14. Rincon F, Kang J, Vibbert M, Urtecho J, Athar MK, Jallo J: Significance of arterial hyperoxia and relationship with case fatality in traumatic brain injury: a multicentre cohort study. J Neurol Neurosurg Psychiatry 2014;85(7):799-805.

15. Brenner M, Stein D, Hu P, Kufera J, Wooford M, Scalea T: 
236 - The Journal of Critical Care Medicine 2021;7(3)

Association between early hyperoxia and worse outcomes after traumatic brain injury. Arch Surg 2012;147(11):1042-1046.

16. Fujita M, Oda Y, Yamashita S, et al: Early-Stage Hyperoxia Is Associated with Favorable Neurological Outcomes and Survival after Severe Traumatic Brain Injury: A Post-Hoc Analysis of the Brain Hypothermia Study. J Neurotrauma 2017;34(8):15651570.

17. Asher SR, Curry P, Sharma D, et al: Survival advantage and $\mathrm{PaO} 2$ threshold in severe traumatic brain injury. J Neurosurg Anesthesiol 2013;25(2):168-173.

18. Ni YN, Wang YM, Liang BM, Liang ZA: The effect of hyperoxia on mortality in critically ill patients: a systematic review and meta analysis. BMC Pulm Med 2019;19(1):53.

19. Helmerhorst HJ, Arts DL, Schultz MJ, et al: Metrics of Arterial Hyperoxia and Associated Outcomes in Critical Care. Crit Care Med 2017;45(2):187-195.

20. de Jonge E, Peelen L, Keijzers PJ, et al: Association between administered oxygen, arterial partial oxygen pressure and mortality in mechanically ventilated intensive care unit patients. Crit Care 2008;12(6):R156.

21. Ortiz-Prado E, Dunn JF, Vasconez J, Castillo D, Viscor G: Partial pressure of oxygen in the human body: a general review. Am J Blood Res 2019;9(1):1-14.

22. Floyd TF, Clark JM, Gelfand R, , et al: Independent cerebral vasoconstrictive effects of hyperoxia and accompanying arterial hypocapnia at 1 ATA. J Appl Physiol (1985) 2003;95(6):24532461.

23. Abate MG, Trivedi M, Fryer TD, et al: Early derangements in oxygen and glucose metabolism following head injury: the ischemic penumbra and pathophysiological heterogeneity.
Available online at: www.jccm.ro

Neurocrit Care 2008;9(3):319-325.

24. Tolias CM, Reinert M, Seiler R, Gilman C, Scharf A, Bullock MR: Normobaric hyperoxia--induced improvement in cerebral metabolism and reduction in intracranial pressure in patients with severe head injury: a prospective historical cohortmatched study. J Neurosurg 2004;101(3):435-444.

25. Ghosh A, Highton D, Kolyva C, Tachtsidis I, Elwell CE, Smith M: Hyperoxia results in increased aerobic metabolism following acute brain injury. J Cereb Blood Flow Metab 2017;37(8):29102920.

26. Rockswold SB, Rockswold GL, Zaun DA, Liu J: A prospective, randomized Phase II clinical trial to evaluate the effect of combined hyperbaric and normobaric hyperoxia on cerebral metabolism, intracranial pressure, oxygen toxicity, and clinical outcome in severe traumatic brain injury. J Neurosurg 2013;118(6):1317-1328.

27. D OB, Nickson C, Pilcher DV, Udy AA: Early Hyperoxia in Patients with Traumatic Brain Injury Admitted to Intensive Care in Australia and New Zealand: A Retrospective Multicenter Cohort Study. Neurocrit Care 2018;29(3):443-451.

28. Damiani E, Adrario E, Girardis M, , et al: Arterial hyperoxia and mortality in critically ill patients: a systematic review and metaanalysis. Crit Care 2014;18(6):711.

29. Nortje J, Coles JP, Timofeev I, et al: Effect of hyperoxia on regional oxygenation and metabolism after severe traumatic brain injury: preliminary findings. Crit Care Med 2008, 36(1):273-281.

30. Taher A, Pilehvari Z, Poorolajal J, Aghajanloo M: Effects of Normobaric Hyperoxia in Traumatic Brain Injury: A Randomized Controlled Clinical Trial. Trauma Mon 2016;21(1):e26772. 